\title{
Review of Teaching Effectively with Zoom: A Practical Guide to Engage Your Students and Help Them Learn
}

Rebecca Eller-Molitas, Elgin Community College

In its first edition, Teaching Effectively with

Zoom, provides timely information on effectively

engaging adult learners in synchronous

instruction via Zoom. This work is based on the experience of the author, his students, and his colleagues at Harvard University as well as research-based principles for effective adult learning. The resource is not a guide to the larger ecosystem of online teaching and acknowledges that live instruction may be only one component of the online teaching and learning experience. This text is targeted toward educators who have at least basic familiarity with Zoom and want to deepen their practice with actionable tips focused on increasing student engagement.

Teaching Effectively with Zoom is organized into four parts. Part I, "Key Ideas," introduces the text and articulates five principles that guide the author's work - including a commitment to student centered instruction which is evident throughout this work. Part II, "Ways Your Students Engage," covers the use of Zoom tools that engage students in instruction by allowing them to interact in various ways. Part III, "Ways You Engage," examines Zoom features that correspond to instructor engagement in synchronous instruction. Finally, Part IV, "Putting it All Together," explores ways to blend synchronous and asynchronous instruction and to build community in the Zoom classroom. Because Zoom technology is rapidly evolving, the author has created a companion website (https://www. teachingeffectivelywithzoom. com/) that is updated regularly as implementation strategies change. The site also includes links to additional resources.

At only 12 chapters and 198 pages, this book is an effective starting point for personal development 
or for program staff who wish to train instructors and tutors in the use of Zoom as a teaching tool. The language used is accessible to tutors who may not have an academic background in education, and ample white space and font size make the text visually appealing. This resource is friendly to educators who are not digital natives because both explanations and images are provided when new technical vocabulary is introduced.

Each section begins with a description of what will be covered and the target skill's usefulness in the virtual classroom. A helpful summary of the chapter's key points follows. For example, Chapter 8, "Present," begins with a brief paragraph on why an educator may want to present during synchronous instruction followed by a bulleted list of presentation tools that will be covered in the chapter such as PowerPoint and Google Slides, Zoom's Whiteboard feature, internal/ external video, document cameras, connected smartphones or tablets, and shared audio. Each tool is individually addressed and complemented with screenshots. Throughout the chapters, readers will find "In Practice" boxes which share experience and tips from faculty and students who use the targeted feature. To further expound upon popular tools, this chapter's "In Practice" section includes both a "high tech edition" and a "low tech edition" example which may be useful to educators who have varying comfort with integrating technology into the classroom.

In conclusion, this resource is appropriate for use by adult education teachers, tutors, and staff who want a hands-on, practical guide to the ways synchronous Zoom instruction can be made more accessible and engaging. Practitioners who lack indepth experience facilitating Zoom learning and those with some experience who wish to increase their skills will find it useful. The book is logically organized and scaffolded. However, readers may find the lack of an index disappointing as it is not easy to quickly identify all resources related to a particular topic of interest. The inclusion of screenshots and illustrations makes the resource easy to navigate, and educators will appreciate that successful use does not require an extensive time commitment. It should be noted that there are no color images in the print book. Quality of the grayscale images is inconsistent, and print screenshots are not always as clear as one would like. The companion website is updated regularly, so screenshots and videos there remain up-todate as Zoom evolves and are of a higher quality. Teaching Effectively with Zoom is unique in both its timeliness and thoroughness; there are few other texts available like it. 